\title{
Inheritance of craniofacial features in Colombian families with class III malocclusion
}

\author{
This article was published in the following Dove Press journal: \\ The Application of Clinical Genetics \\ 29 January 2010 \\ Number of times this article has been viewed
}

\section{Otero \\ L Quintero \\ D Champsaur \\ E Simanca}

Pontificia Universidad Javeriana, Bogotá, Colombia
Correspondence: L Otero

Professor Craniofacial System, Pontificia Universidad Javeriana, Bogotá, Colombia Email lotero@javeriana.edu.co
Introduction: The inheritance of class III malocclusion has been well documented, but the inheritance of craniofacial structures in Colombian families with this malocclusion has been not yet reported.

Patients and methods: The study sample of 25 families comprised 186 untreated orthodontic individuals from 8 to 60 years old. Pedigrees were drawn using Cyrillic software. Complete family histories for each proband were ascertained and the affection status of relatives was confirmed by lateral cephalograms and facial and dental photographs. Analysis of variance and odds ratio test for each parameter was performed to estimate inheritance from parents to offspring and to determine similar phenotypic features in relatives.

Results: The analysis of the pedigrees suggests autosomal dominant inheritance. The craniofacial characteristics that showed more resemblance between parents and offspring were middle facial height, shorter anterior cranial base and mandibular prognathism. In contrast the protrusion of upper lip and maxillary retrusion were the phenotypic features that contributed to class III in the majority of families.

Conclusion: Knowledge of the inheritance of craniofacial phenotypes in class III malocclusion will enable the design of new therapies to treat this malocclusion.

Keywords: inheritance, craniofacial, phenotype, class III malocclusion

\section{Introduction}

Class III malocclusion with mandibular prognathism is a common finding, with prevalence varying by ethnic group. East Asians ${ }^{1}$ show the higher prevalence followed by Africans ${ }^{2}$ and Caucasians. ${ }^{3}$ In Colombia a prevalence of $3 \%$ has been reported for this malocclusion. ${ }^{4}$

Familial studies of mandibular prognathism are suggestive of heredity in the etiology of this condition and several inheritance models have been proposed. The inheritance of phenotypic features in mandibular prognathism was first reported by Strohmayer ${ }^{5}$ and then by Wolff et $\mathrm{al}^{6}$ in their analysis of the pedigree of the Hapsburg family. Suzuki ${ }^{7}$ studied offspring of parents with mandibular prognathism from 243 Japanese families, and reported a frequency of $31 \%$ of this condition if the father was affected, $18 \%$ if the mother was affected and $40 \%$ if both parents were affected. Nakasima et $\mathrm{al}^{8}$ assessed the role of heredity in the development of Angle's Class II and Class III malocclusions and showed high correlation coefficient values between parents and their offspring in the Class II and Class III groups. However the role of cranial base, the midfacial complex and the mandible in the development of class III malocclusion has not been clarified yet. submit your manuscript $\mid$ www.dovepress.com

Dovepress
The Application of Clinical Genetics 2010:3 I-6

(C) 2010 Otero et al, publisher and licensee Dove Medical Press Ltd. This is an Open Access article which permits unrestricted noncommercial use, provided the original work is properly cited. 
Saunders et $\mathrm{al}^{9}$ compared parents with offspring and siblings in 147 families and demonstrated a high level of significant correlations between first-degree relatives. Byard et $\mathrm{al}^{10}$ analyzed family resemblance and found high transmissibility for components related to cranial size and facial height. Lobb ${ }^{11}$ suggested that the shape of the mandible and cranial base are more variable than the maxilla or cranium. Nikolova ${ }^{12}$ studied 251 Bulgarian families and showed a greater paternal influence for head height and nose height. Manfredi et $\mathrm{al}^{13}$ found strong genetic control in vertical parameters and in mandibular structure in twins. In addition Johannsdottir ${ }^{14}$ showed great heritability for the position of the lower jaw, the anterior and posterior face heights, and the cranial base dimensions.

Heritability of craniofacial morphology has also been investigated among siblings; from parents to twins or from parents to off-spring in longitudinal studies. Horowitz et al ${ }^{15}$ demonstrated a significant hereditary component for the anterior cranial base, mandibular body length, lower facial height and total face height. Fernex et $\mathrm{a}^{16}$ found that the sizes of the skeletal facial structures were transmitted with more frequency from mothers to sons than from mothers to daughters. Hunter et $\mathrm{al}^{17}$ reported a strong genetic correlation between fathers and children, especially in mandibular dimensions. Watnick ${ }^{18}$ concluded that the lingual symphysis, the lateral surface of the mandible ramus and the front bend of the jaw have a genetic control. Nakata et a ${ }^{19}$ demonstrated high heritability for 8 cephalometrics variables and reported that the father-offspring relationship was stronger than the mother-offspring relationship.

Although the inheritance and the heritability of craniofacial features have been well documented, the inheritance of these structures in Colombian families with class III malocclusion has been not reported yet. The phenotypic heterogeneity and the variable expression present in this malocclusion could contribute to the fact that the orthodontic therapy in class III malocclusion has not showed consistent results. Moreover, class III malocclusion is a phenotypic manifestation in several pathologies and syndromes. Some cranyosinostosis and cleft lip/palate show relative prognathism, not only in affected individuals but also in unaffected parents. These are strong reasons to conduct studies to attempt to clarify the inheritance phenotype in this malocclusion.

The aims of this study were 1) to estimate the inheritance of craniofacial parameters from parents to offspring in Colombian families with class III malocclusion, and 2) to evaluate the phenotypic features that contribute to class III in each family.

\section{Subjects and methods \\ Sample}

Twenty-five probands with class III malocclusion were identified from the orthodontics clinics at Javeriana University (Bogotá-Colombia). A complete family pedigree for each proband was made and the affected status (class III malocclusion) of other individuals in each family was confirmed by dentist chart, lateral radiographies, facial and dental photographies, and/or dental models. The study protocol was approved by Pontificia Universidad Javeriana ethical committee, and informed consent was obtained from all subjects. Individuals who had syndromes, pathologies or general physical disease were excluded from the study. Subjects who use total prosthesis were excluded, too. The study sample of 25 families comprised 186 orthodontic untreated individuals from 8 to 60 years old ( 25 probands, 22 parents with class III malocclusion, 28 parents without class III malocclusion, 37 affected siblings, 33 unaffected siblings, and 41 affected relatives). Pedigrees were drawn and analyzed using Cyrillic software (see Figure 2).

\section{Cephalometric, dental and facial analysis}

Lateral radiographs and facial photographs were taken and analyzed in all probands, their parents, their siblings (with and without class III) and their affected extended relatives. Confirmed negative ANB angles, straight or concave facial profile, and underbite were prerequisites for enrollment of the proband. The linear and angular measurements were made to determine skeletal and facial diagnostic (McNamara, Steiner, Rickets and Legan's cephalograms; see Figure 1).

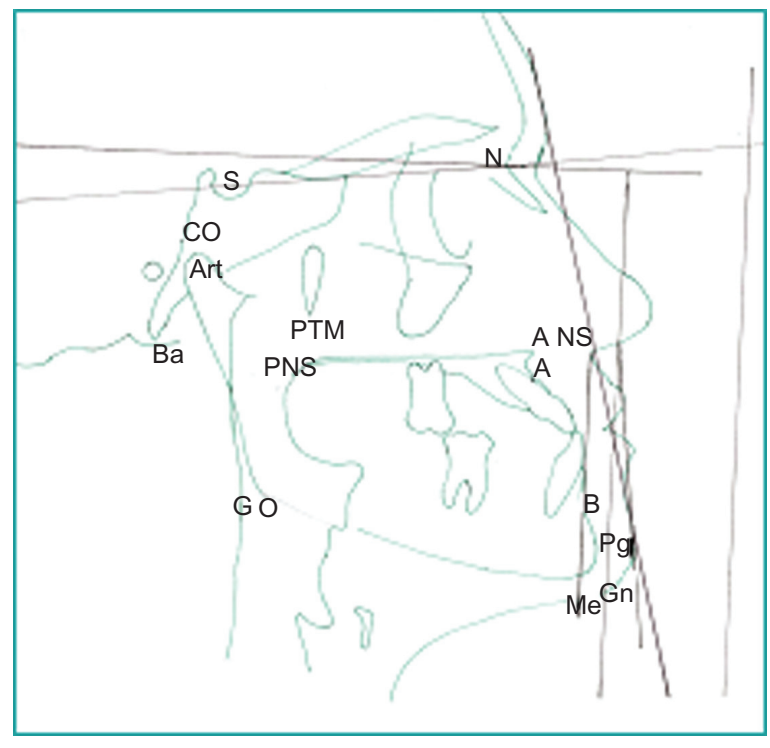

Figure I Cephalometric landmarks. 


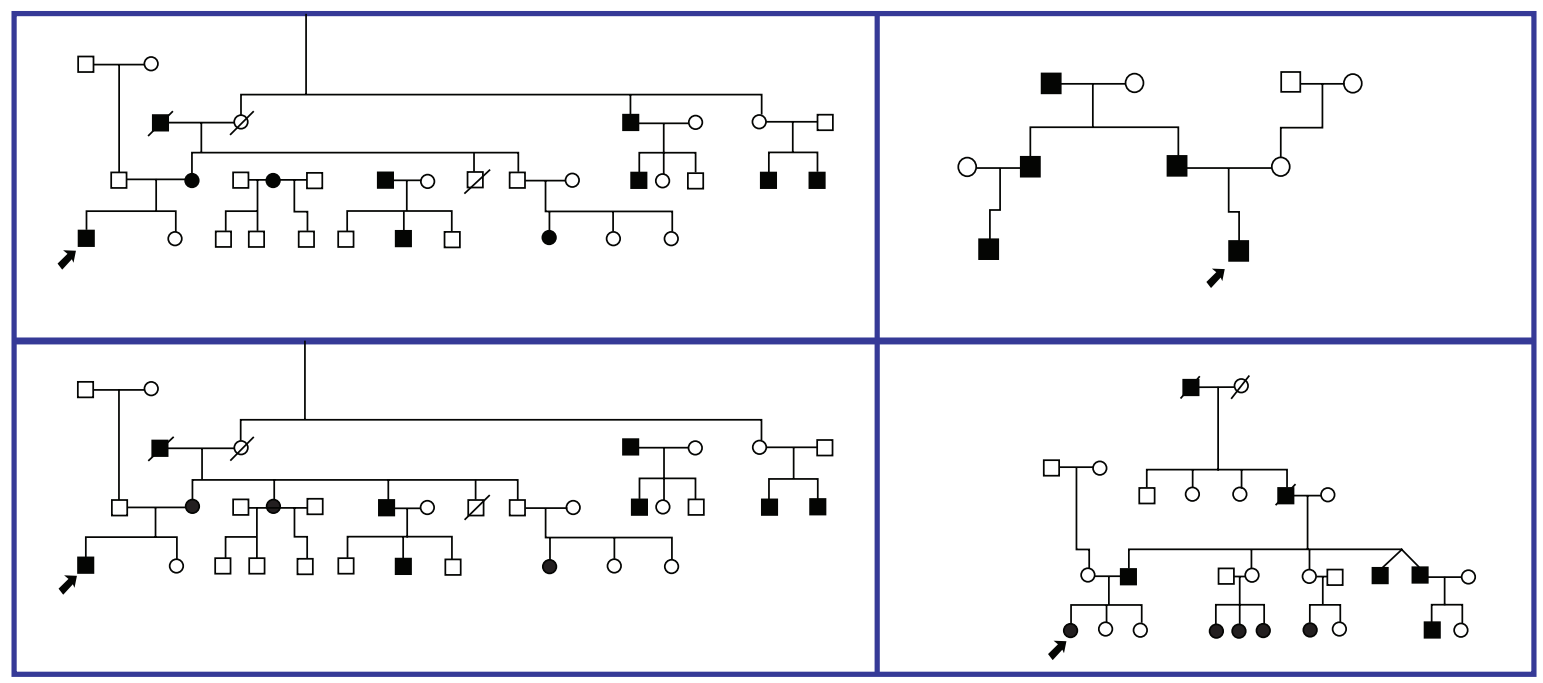

Figure 2 Pedigrees from families with malocclusion.

Dental diagnostics were performed clinically and from dental study models. The classification of malocclusion in all individuals (affected and unaffected relatives) was made upon radiographies and dental model analysis. Class I malocclusion was determined by ANB value of $2^{\circ}$ to $4^{\circ}$ and class II by ANB more than $4^{\circ}$.

\section{Method error}

Fifteen randomly chosen radiographs were retraced by 2 different operators at different intervals. The error method between the replicate tracings was calculated using the interclass correlation coefficient.

\section{Statistical methods}

Analysis of variance and odds ratio test for each parameter were performed to estimate inheritance from parents to offspring. The variance analysis and the odds ratio test were used also to analyze the Class III phenotype in each family, but the hypotheses were different. The accepted hypothesis signified that the feature was similar between probands and relatives with class III malocclusion. The rejected hypothesis signified that the measure was different. The analysis included the statistical values for parents and for parents and offspring separated by genders to determine the significance in each group.

\section{Results}

\section{Method error}

The average of the first reading was 1: 0.0188 (standard deviation $=0.2526$; variation coefficient $=1: 13.4)$; the average of second reading was 2: 0.0027 (standard deviation $=0,3508$; variation coefficient $=2: 19.4$ )

\section{Statistical analysis}

The results of variance analysis and odds ratio (OR) test were summarized in Tables 1, 2 and 3. The two tested statistical methods showed relevant concordance of results.

Several skeletal, facial and dental measures were imprecise because they showed low frequencies. Therefore, facial asymmetry measure (FA), upper incisive inclination (1SN) (1PP), overjet and posterior cross-bite did not give consistent results in the studied families. The OR test confirmed the results obtained by variance analysis.

The results showed the inheritance by gender. Some differences were found between inheritance from parents to daughters or sons. When the facial features were evaluated the middle and inferior facial heights were transmitted from parents to offspring but the highest values in OR test were obtained for the middle facial height (except from fathers to daughters). In addition the position of upper lip and the labiomental sulcus showed inheritance from mothers to offspring.

The unique dental feature that showed inheritance from parents to offspring was the inclination of upper incisive (incisive-silla/nasion plane). Although the variance analysis was imprecise for this feature the odds ratio test showed inheritance from mothers and fathers to offspring (daughters and sons).

The skeletal measures related with the cranial base, the maxilla and the mandible showed inheritance patterns. In contrast, the maxilla position (A-nasion perpendicular) demonstrated inheritance from mothers to offspring in variance analysis, but the odds ratio test showed a low value for this feature from fathers to daughters $(\mathrm{OR}=2)$. However the maxilla size (condilion-A) showed a higher value from mothers to daughters and sons. 
Table I Analysis of variance: facial, dental and skeletal measures inherited from parents to offspring

\begin{tabular}{|c|c|c|c|}
\hline $\begin{array}{l}\text { Cephalometric } \\
\text { measurement }\end{array}$ & Description & From fathers & $\begin{array}{l}\text { From } \\
\text { mothers }\end{array}$ \\
\hline Convexity angle & Profile & $\mathbf{A} \chi^{2}=2,057 \mid$ & $\mathbf{R} \chi^{2}=|4,84| 8$ \\
\hline $\begin{array}{l}\text { NANS: nasion }(\mathrm{N}) \\
\text { to anterior nasal } \\
\text { spine (ANS) }\end{array}$ & $\begin{array}{l}\text { Middle facial } \\
\text { height }\end{array}$ & A $\chi^{2}=2,057$ I & A $\chi^{2}=0,8055$ \\
\hline RICSUP & $\begin{array}{l}\text { Ricketts to } \\
\text { upper lip }\end{array}$ & A $\chi^{2}=6,1538$ & A $\chi^{2}=3,8808$ \\
\hline LMS & $\begin{array}{l}\text { Labiomental- } \\
\text { sulcus }\end{array}$ & $\mathbf{R} \chi^{2}=|5,77| 4$ & A $\chi^{2}=9,9097$ \\
\hline $\begin{array}{l}\text { ANSMe: anterior } \\
\text { nasal spine (ANS) } \\
\text { to menton }\end{array}$ & $\begin{array}{l}\text { Lower facial } \\
\text { height }\end{array}$ & A $\chi^{2}=7,3263$ & A $\chi^{2}=7,2018$ \\
\hline $\begin{array}{l}\text { IMP: lower incisive } \\
\text { to mandibular } \\
\text { plane }\end{array}$ & $\begin{array}{l}\text { Lower dental } \\
\text { inclination }\end{array}$ & $\mathbf{R} \chi^{2}=17,0400$ & $\mathbf{R} \chi^{2}=16,1523$ \\
\hline Overbite & Overbite & $\mathbf{R} \chi^{2}=14,4000$ & $\mathbf{R} \chi^{2}=14,4000$ \\
\hline $\begin{array}{l}\text { SNAR: silla-nasion- } \\
\text { articulare }\end{array}$ & $\begin{array}{l}\text { Cranial base } \\
\text { angle }\end{array}$ & A $\chi^{2}=4,1810$ & A $\chi^{2}=5,1446$ \\
\hline COA: condilion. A & Maxilla size & A $\chi^{2}=9,5000$ & A $\chi^{2}=7,7492$ \\
\hline $\begin{array}{l}\text { COGN: condilion } \\
\text { to Gnation }\end{array}$ & Mandible size & A $\chi^{2}=11,5067$ & A $\chi^{2}=10,8500$ \\
\hline $\begin{array}{l}\mathrm{A} \perp \mathrm{N}: \mathrm{A} \\
\text { perpendicular } \\
\text { nasion }\end{array}$ & Maxilla position & $\mathbf{R} \chi^{2}=12,7644$ & A $\chi^{2}=8,3369$ \\
\hline $\begin{array}{l}\mathrm{Pg} \perp \mathrm{N} \text { : pogonion } \\
\text { perpendicular } \\
\text { nasion }\end{array}$ & $\begin{array}{l}\text { Mandible } \\
\text { position }\end{array}$ & $\mathbf{R} \chi^{2}=22,4095$ & A $\chi^{2}=4,8872$ \\
\hline $\begin{array}{l}\text { SNMP: Silla-nasion- } \\
\text { mandibular plane }\end{array}$ & $\begin{array}{l}\text { Mandible } \\
\text { rotation }\end{array}$ & A $\chi^{2}=8,2000$ & A $\chi^{2}=4,7422$ \\
\hline
\end{tabular}

Analysis of variance: $P(X \leq c)=1-\alpha=95 \%, c=12,5916$ (degrees of freedom $=1^{\circ}$; significance $=5 \%$ ).

Notes: A, accepted hypothesis; $\mathbf{R}$, rejected hypothesis.

The mandible demonstrated differences related to the gender too. A higher inheritance for size of mandible was observed from parents to offspring except for fathers to daughters $(\mathrm{OR}=0.96)$. In addition the position of the mandible (pogonion/perpendicular) showed inheritance from mothers to sons uniquely. The rotation of the mandible (silla/ nasion-mandibular plane) was transmitted from fathers and mothers to daughters, but was not inherited by sons.

The analysis of variance was used to evaluate the phenotypic features that contribute to class III in each family. The probands were compared with their parents, and relatives (siblings, cousins, grandparents, uncles and aunts) in each family. The same features (facial, dental and skeletal) that showed inheritance from parents to offspring demonstrated similar cephalometric values in the relatives with class III malocclusion. However the size and position of the mandible exhibited different cephalometric values in the studied families, confirming the phenotypic heterogeneity present in this malocclusion (see Table 3).

\section{Discussion}

The findings reported in this study confirm that craniofacial morphology is inherited in class III malocclusion, although the phenotype of parents and offspring do not show the same malocclusion. Moreover the skeletal and facial features demonstrated different risk of inheritance according to the gender.

The skeletal features demonstrated more probability of inheritance than dental and facial features. The anterior cranial base showed inheritance from parents to sons. The size and angle of cranial base were inherited features, but the size of anterior cranial base showed the highest probability for heredity from mothers and fathers to sons while the posterior cranial base demonstrated higher inheritance from mothers to daughters. Similar results were reported previously by Johannsdottir et $\mathrm{al}^{14}$ The size and angle of cranial base seems to be related with the increase in length and breadth of the mandible in the development of Class III malocclusions..$^{20,21}$ Additionally pathologies with relative mandibular prognathism like cleft lip palate seem be associated to short cranial base from unaffected parents to daughters and sons. ${ }^{22}$

The cephalometrics parameters that evaluated mandible size (CoGn, Ar Go, GoGn) demonstrated inherited patterns from parents to offspring except from fathers to daughters. Additionally the position and rotation of the mandible were also inherited features. These results agree with Saunders et $\mathrm{al}^{9}$ who suggested that data from fathers are slightly better than data from mothers in predicting the son's measurement, particularly for mandibular dimensions. Previous reports showed similar results in different malocclusions ${ }^{14,15}$ and for class III malocclusion. ${ }^{9}$ Furthermore, these findings showed that sexual dimorphism reported in class III malocclusion produce changes in the mandible size and shape. ${ }^{23,24}$

The middle facial height showed high inheritance values from parents to offspring but it was not transmitted from fathers to daughters. In the same way, Manfredi et a ${ }^{13}$ reported high heritability for total anterior facial height in twins; and Johannsdottir et al ${ }^{14}$ reported high inheritance for total anterior facial height from parents to offspring but not for mothers to daughters. However it is important to note that although these authors did not study class III malocclusion, deviations in middle facial height may be associated with the retrusion of maxilla observed frequently in class III.

The evaluation of the phenotypic features that contribute to class III in each family showed similar measures in facial 
Table 2 Odds ratio: analysis of facial, dental and skeletal measures inherited from parents to offspring

\begin{tabular}{|c|c|c|c|c|c|}
\hline Cephalometric measurement ${ }^{a}$ & Description & $\begin{array}{l}P^{*} \text { from fathers } \\
\text { to sons }\end{array}$ & $\begin{array}{l}p \text { from mothers } \\
\text { to sons }\end{array}$ & $\begin{array}{l}p \text { from fathers } \\
\text { to daughters }\end{array}$ & $\begin{array}{l}p \text { from mothers } \\
\text { to daughters }\end{array}$ \\
\hline Convexity angle & Profile & 6,00 & 0,56 & 0,96 & 3,11 \\
\hline NANS & Middle facial height & 16,00 & 42,00 & 0,16 & 12,00 \\
\hline RICSUP & Ricketts sup lip & 4,44 & 3,11 & 0,44 & 0,00 \\
\hline RICINF & Ricketts inf Lip & 0,96 & 3,11 & 0,96 & 3,11 \\
\hline LMS & Labiomental-sulcus & 2,00 & 3,11 & 2,00 & 3,11 \\
\hline ANSMe & Lower facial height & 0,96 & 0,56 & 4,44 & 3,11 \\
\hline ISilla Nasion & Upper incisive position & 16,00 & $\mathrm{I}, \mathrm{II}$ & 5,00 & 2,75 \\
\hline IPalatine Plane & Upper incisive position & 12,00 & 3,75 & 2,00 & 0,00 \\
\hline IMP & Low incisive position & 0,96 & $\mathrm{I}, \mathrm{II}$ & 2,00 & $\mathrm{I}, 3 \mathrm{I}$ \\
\hline MR & Molar relation & 0,00 & 0,00 & 0,00 & 0,00 \\
\hline Overjet & Overjet & 0,04 & 0,12 & 0,00 & 0,00 \\
\hline overbite & Overbite & 0,34 & 0,14 & 0,44 & 0,54 \\
\hline PCB & Posterior cross bite & 0,00 & 0,00 & 0,96 & $\mathrm{I}, \mathrm{II}$ \\
\hline ANB & ANB angle & 0,96 & 8,75 & 2,00 & 8,75 \\
\hline ARPTM: articulare-pterigopalatine & Anterior cranial base & 12,00 & 22,00 & 0,44 & 3,11 \\
\hline PTMN: pterigopalatine-nasion & Posterior cranial base & 0,16 & $|, 3|$ & 0,44 & 8,75 \\
\hline SNAR & Cranial base angle & 2,00 & 3,11 & 0,96 & 8,75 \\
\hline COA & Maxilla size & 0,44 & 3,11 & 0,44 & 3,11 \\
\hline PSN-ASN & Maxilla size & 0,44 & $|, 3|$ & 0,96 & 0,19 \\
\hline COGN & Mandible size & 2,00 & 22,00 & 0,44 & 8,75 \\
\hline ARGO: articulare-gonion & Mandible size & 0,44 & 0,56 & 2,00 & 8,75 \\
\hline GOGN: gonion-gnation & Mandible size (body) & 12,00 & 8,75 & 0,16 & 3,11 \\
\hline $\mathrm{A} \perp \mathrm{N}$ & Maxilla position & 0,44 & 0,19 & 2,00 & 0,56 \\
\hline $\mathrm{Pg} \perp \mathrm{N}$ & Mandible position & 2,00 & 8,75 & 0,16 & 0,00 \\
\hline SNMP & Mandible rotation & 0,96 & $|, 3|$ & 4,44 & 8,75 \\
\hline
\end{tabular}

a See Table I for definitions.

" $P$ is the proportion of cases with class III malocclusion.

Table 3 Variance analysis: family's phenotype

\begin{tabular}{llll}
\hline Variable & Description & $\begin{array}{l}\text { First degree } \\
\text { relative }\end{array}$ & $\begin{array}{l}\text { Extended } \\
\text { relative }\end{array}$ \\
\hline $\begin{array}{l}\text { Convexity } \\
\text { angle }\end{array}$ & Profile & A $\chi^{2}=2,7272$ & A $\chi^{2}=6,2135$ \\
PRTEIN & Middle facial height & A $\chi^{2}=2,964$ I & A $\chi^{2}=1,3073$ \\
RICSUP & Ricketts sup lip & $\mathbf{A} \chi^{2}=6,3243$ & A $\chi^{2}=3,26$ II \\
ML & Labiomental-sulcus & $\mathbf{A} \chi^{2}=1,5886$ & $\mathbf{R} \chi^{2}=15,9498$ \\
ALFAINF & Lower facial height & $\mathbf{A} \chi^{2}=5,5701$ & $\mathbf{A} \chi^{2}=0,8033$ \\
IMP & Low incisive position & $\mathbf{A} \chi^{2}=9,6120$ & $\mathbf{A} \chi^{2}=2,3298$ \\
SNAR & Cranial base angle & $\mathbf{A} \chi^{2}=3,5315$ & $\mathbf{A} \chi^{2}=5,1104$ \\
COA & Maxilla size & $\mathbf{A} \chi^{2}=10,7405$ & $\mathbf{A} \chi^{2}=6,3442$ \\
COGN & Mandible size & $\mathbf{R} \chi^{2}=16,6988$ & $\mathbf{R} \chi^{2}=17,5687$ \\
A $\perp$ N & Maxilla position & $\mathbf{A} \chi^{2}=7,7604$ & $\mathbf{A} \chi^{2}=5,2659$ \\
Pg $\perp$ N & Mandible position & $\mathbf{A} \chi^{2}=5,5095$ & $\mathbf{R} \chi^{2}=16,6189$ \\
SNMP & Mandible rotation & $\mathbf{A} \chi^{2}=3,5421$ & $\mathbf{A} \chi^{2}=4,2535$ \\
\hline
\end{tabular}

Notes: $c=12,5916$. Accepted (A): $x<c$. Rejected $\AA: c<x$. and skeletal features in relatives with this malocclusion. The facial height (middle and lower), the retrusion of upper lip, the size of cranial base angle, and the retrusion of the maxilla showed a similar phenotype in the group of individuals with class III malocclusion. The phenotype of class III maloclusión seems to be characteristic for each ethnic group. Singh et a ${ }^{25}$ reported that Koreans with class III malocclusion had shorter anterior cranial base and more pronounced midfacial retrognathia compared with White Americans. Besides, some ethnic differences between Chinese and Caucasians with class III malocclusion ${ }^{26}$ and between Japanese and Caucasian females have been reported..$^{27}$ Additionally Watanabe et a ${ }^{28}$ showed high occurrence of mandibular prognathism in Asian families. However ethnic differences between the Latin-American and other groups have not been studied yet.

Considering that the cephalometric measurements have some limitations for studying the morphology of 
craniofacial structures, it is necessary to investigate the craniofacial morphology through three-dimensional analyses which allows the inheritance of these structures in different malocclusions to be identified.

\section{Conclusions}

Skeletal features such as anterior cranial base size, maxilla and mandible size, and maxilla and mandible position demonstrated a higher probability of inheritance than dental and facial features in class III malocclusion. The phenotype showed by the affected members in families with class III malocclusion suggested a sexual dimorphism for this malocclusion. Future studies should be directed to clarifying the relationship between the phenotype and genotype in several ethnic groups with different malocclusions.

\section{Acknowledgments}

We are very grateful to the individuals who contributed samples for this study.

This study was supported by ICGEB grant CRP/ COL04-03.

\section{Disclosures}

The authors declare no conflicts of interest.

\section{References}

1. Allwright WC, Bundred WH. A survey of handicapping dentofacial anomalies among Chinese in Hong Kong. Int Dent J. 1964;14:505-519.

2. Garner LD, Butt MH. Malocclusion in black American and Nyeri Kenyans. An epidemiologic study. Angle Orthod. 1985;55:139-146.

3. Emrich RE, Brodie AG, Blayney JR. Prevalence of class I, class II, and class III malocclusions (Angle) in an urban population; an epidemiological study. J Dent Res. 1965;44:947-953.

4. Thilander B, Peña L, Infante C, Parada S, Mayorga C. Prevalence of malocclusion and orthodontic treatment need in children and adolescents in Bogota, Colombia. An epidemiological study related to different stages of dental development. Eur J Orthod. 2001;23:2:145-151.

5. Strohmayer W. Die Vereburg des Hapsburger Familientypus. Nova Acta Leopoldina. 1937;5:219-296.

6. Wolff G, Wienker TF, Sander H. On the genetics of mandibular prognathism: analysis of large European noble families. J Med Genet. 1993;30:112-116.

7. Suzuki S. Studies on the so-called reverse occlusion. J Nihon Univ Sch Dent. 1961;3:51-58.

8. Nakasima A, Ichinose M, Nakata S, Takahama Y. Hereditary factors in the craniofacial morphology of Angle's Class II and Class III malocclusions. Am J Orthod. 1982;82:150-156.

The Application of Clinical Genetics

\section{Publish your work in this journal}

The Application of Clinical Genetics is an international, peer-reviewed open access journal that welcomes laboratory and clinical findings in the field of human genetics. Specific topics include: Population genetics; Functional genetics; Natural history of genetic disease; Management of genetic disease; Mechanisms of genetic disease; Counselling and
9. Saunders SR, Popovich F, Thompson GW. A family study of craniofacial dimensions in the Burlington Growth Centre sample. Am J Orthod. 1980;78:394-403.

10. Byard PJ, Poosha DV, Satyanarayana M, Rao DC. Family resemblance for components of craniofacial size and shape. J Craniofac Genet Dev Biol. 1985;5:229-238.

11. Lobb WK. Craniofacial morphology and occlusal variation in monozygotic and dizygotic twins. Angle Orthod. 1987;57:219-233.

12. Nikolova M. Similarities in anthropometrical traits of children and their parents in a Bulgarian population. Ann Hum Genet. 1996;60:517-525.

13. Manfredi C, Martina R, Grossi GB, Giuliani M. Heritability of 39 orthodontic cephalometric parameters on MZ, DZ twins and MN-paired singletons. Am J Orthod Dentofacial Orthop. 1997;111: $44-51$.

14. Johannsdottir B, Thorarinsson F, Thordarson A, Magnusson TE. Heritability of craniofacial characteristics between parents and offspring estimated from lateral cephalograms. Am J Orthod Dentofacial Orthop. 2005;127:200-207.

15. Horowitz S. Osborne R. De George F. A cephalometric study of craniofacial variation in adults twins. Angle Orthod. 1960;30:1-5.

16. Fernex E. Hauenstein P. Roche M. Heredity and craniofacial morphology. Transactionns of the European Orthodontic society. 1967: 239-257.

17. Hunter W. Ballouch D. Lamphier D. The heritability of attained growth in the human face. Am J of Orthod. 1970;58:128-134.

18. WatnicK S. Inheritance of facial morphology. Angle Orthod. 1972;42:339-351.

19. Nakata N, Yu PI, Davis B, Nance WE. The use of genetic data in the prediction of craniofacial dimensions. Am J Orthod. 1973;63:471-480.

20. Malinowski A. Changes in dimensions and proportions of the human mandible during fetal period. Coll Antropol. 1983;7:65-70.

21. Singh GD, McNamara Jr JA, Lozanoff S. Morphometry of the cranial base in subjects with Class III malocclusion. J Dent Res. 1997;76: 694-703.

22. Perkiomaki MR, Yoon YJ, Tallents RH, et al. Association of distinct craniofacial features in nonsyndromic cleft lip and palate family members. Cleft Palate Craniofac J. 2003;40:397-402.

23. Chang JZ, Chen YJ, Chang FH, et al. Morphometric analysis of mandibular growth in skeletal Class III malocclusion. J Formos Med Assoc. 2006;105:318-328.

24. Baccetti T, Reyes BC, McNamara JA Jr. Gender differences in Class III malocclusion. Angle Orthod. 2005;75:510-520.

25. Singh GD, McNamara JA Jr, Lozanoff S. Comparison of mandibular morphology in Korean and European-American children with Class III malocclusions using finite-element morphometry. J Orthod. 2000;27: 135-142.

26. Ngan P, Hagg U, Yiu C, Merwin D, Wei SH. Cephalometric comparisons of Chinese and Caucasian surgical Class III patients. Int J Adult Orthodon Orthognath Surg. 1997;12:177-188.

27. Ishii N, Deguchi T, Hunt NP. Craniofacial differences between Japanese and British Caucasian females with a skeletal Class III malocclusion. Eur J Orthod. 2002;24:493-499.

28. Watanabe M, Suda N, Ohyama K. Mandibular prognathism in Japanese families ascertained through orthognathically treated patients. Am J Orthod Dentofacial Orthop. 2005;128:466-470.

\section{Dovepress}

ethical issues; Animal models; Pharmacogenetics; Prenatal diagnosis; Dysmorphology. The manuscript management system is completely online and includes a very quick and fair peer-review system, which is all easy to use. Visit http://www.dovepress.com/testimonials.php to read real quotes from published authors. 